\title{
A DINÂMICA POLÍTICA, ECONÔMICA E SOCIAL DO RIO SÃO FRANCISCO E DO SEU VALE

\author{
José Vieira Camelo Filho
}

\begin{abstract}
Resumo: O rio São Francisco sempre foi um canal importante de ligação entre o Nordeste, Sudeste e Centro-Oeste, feita através da navegação fluvial. Estrategicamente, esse rio e seus afluentes contribuíram para o controle e o povoamento do interior, onde, ao longo da história, constituíram-se os grandes latifúndios e os pequenos minifúndios, ambos responsáveis pelo atraso econômico e social do Vale. Sua economia, até a primeira metade do século XX, foi ancorada na pecuária extensiva e na agricultura de subsistência. A posse ou acesso à terra, para a maioria da população, continua sendo um grande desafio para a sociedade. Nos últimos 50 anos, a água do Velho Chico tornou-se a maior riqueza do Vale e a matéria-prima mais importante para o seu desenvolvimento, que, efetivamente, iniciou com a geração de energia em Paulo Afonso. A partir das décadas de 1980 e 1990, 0 processo de irrigação se intensificou, em particular, visando a produção de frutas nos Perímetros de Irrigação de Petrolina e Juazeiro, Oeste da Bahia, e com Projeto Jaíba e Pirapora, em Minas Gerais. Contudo, nos últimos anos, o Projeto de Transposição de água do São Francisco para outras bacias hidrográficas do semi-árido vem ganhando destaque.
\end{abstract}

Palavras-chave: Rio São Francisco; Navegação; Água; Terra; Desenvolvimento; Irrigação; Propriedade.

\section{Introdução}

Neste trabalho procuramos situar o rio São Francisco e seu Vale nos contextos político, econômico, social e geográfico do Brasil, tendo em vista as contradições presentes em nossa sociedade. O Velho Chico serviu de canal para povoamento e controle do interior brasileiro ao longo da história e de ligação entre 0 Nordeste e o Sudeste, atravessando o semi-árido nordestino. A primeira medida concreta para o desenvolvimento do Vale se deu com a criação da Companhia Hidrelétrica do São FranciscoCHESF, em 1945, e da Comissão do Vale do São FranciscoCVSF, em 1948. A CVSF foi substituída pela SUVALE, em 1967, que, por sua vez, originou a Companhia de Desenvolvimento do Vale do São Francisco (CODEVASF), criada em 1974, com a função de desenvolver o Vale, sobretudo no campo da agricultura irrigada, com destaque para a produção de frutas: banana, melão, melancia, ata, manga, uva, além de produzir vinho, sucos e sementes. Mas o Projeto mais antigo do Vale foi apresentado em 1847; trata-se da transferência de parte da água do Velho Chico para outras bacias do semi-árido. Após 158 anos, encontra-se ainda em fase de implantação, com 0 nome de Projeto de Integração do Rio São Francisco com Bacias Hidrográficas do Nordeste Setentrional.

\section{O rio São Francisco, o caminho estratégico do Brasil}

A relação do Estado com o rio São Francisco vem do período colonial devido a sua posição estratégica no que diz respeito à ocupação e controle do território por parte da Coroa Portuguesa. O povoamento do Vale do São Francisco deu-se lentamente porque, em termos econômicos, os negócios com 0 açúcar estavam em primeiro plano, tanto que SANTOS (1985) destaca que 0 açúcar é um gênero de importância básica no mercado no mercado mundial a partir do século XVI e o mesmo era produzido no litoral brasileiro. A ocupação da região, da foz do rio e que se estende cerca de $300 \mathrm{~km}$ para o interior, iniciou-se com o desenvolvimento da pecuária extensiva que, por sua vez, teve grande importância para a atividade açucareira, realizada na costa litorânea. $O$ rio era mais um acidente geográfico encontrado pelos portugueses desde o litoral do Atlântico, no entanto permitiu a penetração para 0 interior do território e, assegurava o controle e o povoamento dele pela Coroa Portuguesa que ampliava a sua expansão para além do litoral.

Geograficamente a plantação de cana para a produção de açúcar estendeu-se pela área coberta pela Mata Atlântica, também conhecida como Zona da Mata na faixa litorânea do litoral de Pernambuco, Alagoas e Recôncavo Baiano, e só mais tarde chegou ao litoral norte do Rio de Janeiro, região de Campos dos Goytacazes. A introdução da cana-de-açúcar no Brasil ocorreu ainda na primeira metade do século XVI, passou por um processo de estagnação nos séculos XVII e XVIII, contudo continuou sendo plantada nas mesmas regiões e no século XX se expandiu por todo o Brasil, particularmente no Sudeste. Por outro lado, não podemos esquecer da plantação de subsistência para a produção 
de rapadura e aguardente (cachaça) distribuída por todo interior do país, inclusive no sertão nordestino e no Vale do São Francisco. Esse processo vem ocorrendo desde o período colonial e dura até os dias atuais.

THERY (1980) lembra que o gado, além de servir para a alimentação, também representava um elemento indispensável nas atividades agrícolas, nos serviços de transporte, portanto, tinha forte relação com o cotidiano das atividades desenvolvidas pelo homem do meio rural. ABREU (1975) destaca essa importância, tanto que é responsável pela civilização do couro no interior do país. 0 gado tinha papel preponderante nas atividades ligadas aos engenhos, por exemplo, com 0 couro fazia-se 0 bangüê que aparava a garapa no momento da moagem da canade-açúcar e; 0 engenho era movimentado por tração animal, que recebia a denominação de "trapiche". A expansão da atividade pecuária contribuiu para que no século XVIII todo o Vale estivesse povoado. FURTADO (1972) completa afirmando que a pecuária surge fundamentalmente para satisfazer a demanda de carne, de animais de tração e carga, criada tanto por empresas agromercantis quanto pela exportação mineira.

O rio São Francisco serviu de via para transporte de alimento (milho, feijão, carne seca, rapadura, farinha) destinado ao suprimento das minas de ouro; por ele seguiam escravos e garimpeiros vindos de outras regiões. Serviu também para evasão (saída) de ouro que chegava até Salvador. Graças a este particular, o controle da navegação pelo rio tornou-se mais incisivo por parte da Coroa portuguesa que chegou a proibir 0 tráfego de mercadorias, 0 ouro em particular, sendo permitido apenas 0 transporte de alimentos destinados ao abastecimento das minas. No período da mineração tivemos uma forte expansão da pecuária no Vale e um significativo aumento da população, tornando-se a região a mais povoada da colônia depois das áreas produtoras de açúcar. Com isso, formaram-se vários núcleos de povoamentos que deram origem a cidades espalhadas em toda a extensão do rio São Francisco e de seus afluentes.

O ciclo econômico da mineração chegou ao fim, o domínio colonial português também e 0 rio São Francisco continuou pulsando como se fosse a artéria aorta do coração do interior do território brasileiro. Entretanto, o Vale continuou sem qualquer transformação do seu cotidiano econômico historicamente ancorado na pecuária extensiva e na agricultura de subsistência. Dessa forma, a região manteve o processo de povoamento iniciado no período colonial. Por conta da atividade pecuária desenvolvida no Vale, o rio São Francisco recebeu a denominação de "Rio dos Currais", e a partir da Independência do Brasil, passou a ser chamado de "Rio da Integração Nacional", porque proporcionou a ligação direta entre o Nordeste e Sudeste do país. A navegação se intensificou em todo o percurso navegável do rio, apesar da simplicidade dos seus barcos; lembramos que os primeiros barcos a vapor só foram introduzidos no São Francisco em 1866.

A posição geográfica do rio São Francisco sempre foi considerada estratégica pelos seus estudiosos em relação ao povoamento e controle do interior, tanto no período colonial como também após a Independência. BURTON (1977) expressa bem essa forma de ver o rio, em suas pesquisas realizadas na década de 1860 (século XIX), em que ele procura analisar o seu papel como canal de comunicação entre as regiões litorâneas e 0 sertão, entre o Norte e o Sul do país, facilitando a realização do comércio e a colonização. De acordo com esse autor, o São Francisco evitava a escassez, ao assegurar o escoamento dos excedentes das regiões centrais, principalmente nos períodos de estiagem que prejudicavam a agricultura ou quando, por ventura, a faixa litorânea fosse bloqueada por forças exógenas. E conclui que desta forma se completa o ciclo estratégico de que o Império necessitava grandemente para preservar a sua integridade.

A preocupação estratégica apontada por Burton, tendo em vista um possível bloqueio da faixa litorânea, só veio a se tornar realidade bem mais tarde, com a eclosão da Segunda Guerra, em 1939. O governo brasileiro, no decorrer da Segunda Guerra, estabeleceu que a navegação do São Francisco seria uma via estratégica para assegurar o suprimento de mercadorias no interior do país, em caso de ocupação do seu litoral por tropas estrangeiras. O coronel FIGUEIREDO (1941) também destaca a incontestável influência do São Francisco (desde os tempos remotos) para a história da civilização brasileira, e lembra que, apesar da sua importância, o rio vem sendo tratado com descaso pelo governo brasileiro, tanto que, já na década de 1930, ele agonizava em decorrência da escassez do volume líquido, da falta de drenagem no leito entulhado de areia, paus e outros entulhos carregados pelas torrentes. Mesmo com esse contexto, todas as atividades econômicas relacionadas com 0 rio sempre tiveram estreita ligação com o Estado, desde o período colonial; por isso, recebeu um destaque especial em relação aos demais rios do Brasil.

A sua navegação fluvial tinha dois percursos: da foz a Piranhas, na sua porção inferior, e de Juazeiro (BA) a Pirapora (MG), com 1371 km de extensão, sendo feita com barcos simples; em muitos trechos, adotava-se a tradição indígena de navegar, usando pequenos barcos e só a partir de 1866, foram introduzidos os primeiros vapores. MACHADO (2002) em seu estudo a res- 
peito da navegação do São Francisco lembra que o Saldanha Marinho foi o navio mais importante que navegou no rio São Francisco. Realizou a sua primeira viagem em 19 de janeiro de 1871, no rio das Velhas. Em seguida, o Saldanha passou a navegar no rio São Francisco e só encerrou às suas atividades no final da década de 1970, com a construção da barragem de Sobradinho. No século XX outro navio fez história, trata-se do Benjamim Guimarães, construído nos EUA em 1913, que recentemente foi reformado no porto de Pirapora e, em 2005, voltou a navegar em um pequeno trecho das águas do Velho Chico para o transporte de turistas. Esses navios transportavam passageiros e mercadorias e estabeleciam o intercâmbio entre as regiões Nordeste, Sudeste e Centro-Oeste.

\section{O cotidiano da navegação do rio São Francisco na primeira metade do século $X X$}

$\mathrm{O}$ transporte no interior do Brasil, até a primeira metade do século $\mathrm{XX}$, era precário, exceto em alguns curtos percursos atingidos por ferrovias. A navegação fluvial, por muitos anos, era a única alternativa de transporte em larga extensão do território brasileiro (inclusive no Vale do São Francisco), tendo os seus rios como as principais vias. De acordo com os dados do Documento Plano de Valorização Econômica do Vale do São Francisco (1963), o movimento médio anual de cargas transportadas entre 1938 e 1948 girou em torno de 40000 ton, o que demonstra um processo produtivo estático ou uma economia "paralisada". Segundo o citado documento este volume de carga teria que se elevar a 100000 ton, para justificar economicamente a existência da navegação fluvial na bacia do São Francisco. Frente a tais informações, a Comissão do Vale do São Francisco (CVSF) fez um estudo mais sistematizado a respeito da navegação do rio São Francisco e de seus afluentes, em que propôs uma racionalização da sua navegação e onde estabelecia um novo parâmetro operacional.

Conforme os estudos da CVSF, a navegação deveria dividir-se em 8 linhas. Quatro linhas deveriam operar no rio São Francisco, com duas de cargas, uma mista e a última só para passageiros. Quatro linhas deveriam operar nos afluentes, todas mistas para carga e passageiros. Verificou-se que havia a obrigatoriedade da fila de saída nos portos extremos dos rios (Pirapora e Juazeiro), pela qual o navio só podia partir em certos dias do mês, levando em conta a sua ordem de chegada. Dessa forma, alguns ficavam até 10 dias parados, cerca de $50 \%$ do seu tempo gasto para realizar o percurso, enquanto gastavam $20 \%$ para carregar e $30 \%$ na viagem propriamente dita. A partir dessa constatação estabeleceu-se uma nova tabela de chegada e partida para reduzir o tempo de espera dos navios. Outro elemento que diz respeito aos custos era o elevado número de tripulantes por navio, 39 em média. De acordo com o estudo da CVSF, apenas 16 pessoas poderiam realizar as tarefas de um navio, embora a tripulação fosse responsável por dois carregamentos num dia e o combustível das embarcações fosse lenha.

A navegação do rio São Francisco também era feita por inúmeros barcos de pequeno e médio porte, de propriedade particular, que viajavam até $100 \mathrm{~km}$, sendo difícil mensurar o volume de cargas e o número de passageiros por eles transportados, pois não existem dados a respeito. A navegação de longo percurso do rio São Francisco e de alguns de seus afluentes era realizada por empresas de maior porte. Duas dessas empresas pertenciam aos governos da Bahia e de Minas Gerais, respectivamente, a Viação Baiana do São Francisco e a Navegação Mineira de Viação de Pirapora, havendo ainda uma terceira empresa privada. De acordo com os relatórios da CVSF, estas empresas apresentaram um equilibrio entre si no que diz respeito ao volume de cargas e ao número de passageiros transportados no período entre 1942 e 1948, com as seguintes médias anuais: a Viação Baiana transportou 16165 ton e 16311 passageiros, a Viação Mineira 17611 ton e 20219 passageiros e a Companhia e Indústria, 14.365 t e 17100 passageiros.

No quinquêenio 1952-1956, a CVSF elaborou um amplo Plano de ação para a navegação fluvial do Vale, com vista à elevação de sua produtividade que continuava no mesmo nivel da década anterior. Entre as medidas, destacava-se a ampliação da capacidade portuária pela aquisição de novos equipamentos (guinchos, novas embarcações, etc), concretagem dos portos já existentes, construção de novas unidades e aumento dos armazéns. Assim seria possível elevar a oferta dos serviços de transporte fluvial, para chegar à década de 1960 transportando 100000 ton ao ano. Para alcançar essas metas, o governo federal extinguiu as empresas de navegação e em 24 de janeiro de 1963, criou a Companhia de Navegação do São Francisco (FRANAVE), com sede na cidade de Pirapora-MG e escritório de representação em Juazeiro (BA).

A FRANAVE iniciou o século XXI com uma capacidade instalada de transporte para 150.000 ton de carga a granel e de convés por ano, com uma frota composta de 8 empurradores de 540 HP e 62 chatas, além de um estaleiro para a construção de navios e manutenção de sua frota na cidade de Juazeiro. A navegação do São Francisco tem ligação com ferrovias e rodovias tanto no Nordeste quanto no Sudeste. Aplica tarifas $25 \%$ menores 
do que as do transporte rodoviário, porém continua operando precariamente. 0 problema da navegabilidade do rio nunca foi considerado com as devidas medidas políticas que ele exige, embora se conheça seus limites e particularidades; contudo, sua importância sempre foi destacada nos pronunciamentos governamentais que prometeram tomar as medidas cabiveis para assegurar a sua continuidade.

A questão da navegação do rio São Francisco e de seus afluentes sempre fez parte da agenda oficial, mesmo após o final da Segunda Guerra Mundial, quando a opção pelo transporte rodoviário já estava delineada. Porém, durante toda a década de 1950, esse problema foi posto e o governo apresentava novas propostas para vitalizar a navegação fluvial do Velho Chico. Tratase de um problema de difícil solução, que esteve sempre presente na pauta e na agenda de todos os governos do Brasil na primeira metade do século XX e prosseguiu na fila de espera. Na década de 1960, não foi diferente, o governo continuou tentando dar respostas a esse problema histórico que todos se sentem na obrigação de resolver. No decorrer das décadas de 1970 e 1980, as questões do passado continuavam presentes, ou seja, sem solução e, nos anos 1990, voltaram à baila no programa "Avança Brasil", nos governos de Fernando Henrique Cardoso. A navegação interior (fluvial) do Brasil, segundo os dados do Anuário Estatístico do Brasil de 1938, contava com $43955 \mathrm{~km}$ de extensão, sendo que a bacia do São Francisco, ocupava a terceira posição no país, com $4135 \mathrm{~km}$ ou $9,41 \%$, superada pela bacia do Amazonas que tinha $57,89 \%$, ou $25446 \mathrm{~km}$, e pela bacia do Nordeste, responsável por um trecho navegável de $4498 \mathrm{~km}, 0$ equivalente a $10,23 \%$ do total.

Segundo os dados do IBGE de 1977, o país ainda possuía uma rede fluvial permanente de $35000 \mathrm{~km}$, mais $15800 \mathrm{~km}$ no período das cheias. 0 Sudeste tem apenas $1600 \mathrm{~km}$, acrescidos de mais $410 \mathrm{~km}$ durante as chuvas. A concorrência com a rodovia que se ampliou por todo território nacional e as péssimas condições da navegação nos rios, devido ao descaso com essas vias que operavam com equipamentos ultrapassados e portos inadequados, contribuiu para o fraco desempenho do transporte fluvial, sobretudo no rio São Francisco (Fig. 1). No decorrer da década de 1970, nunca ultrapassou o total de 34000 ton transportadas. Só nos anos de 1980, é que houve uma significativa melhora no seu desempenho. Em 1988, alcançou 115901 ton transportadas, caindo, no ano seguinte, para 94063 ton. Quanto às demais bacias, a situação não era diferente, embora tenha havido certo crescimento de carga transportada a partir de 1979, sendo a bacia Amazônica aquela que apresentou o maior aumen- to no período.

É importante destacar que no o período entre 1979 e 1989 o transporte hidrográfico do rio São Francisco apresentou um significativo crescimento de carga transportada, passando de 33267 ton em 1980, para 115901 ton, em 1988, com forte redução no ano seguinte para 94063 ton, equivalente a $18,84 \%$. De acordo com os dados do Ministério dos Transportes, em todas as bacias houve redução de carga em relação ao ano anterior, exceto a bacia de Sudeste. Esta operou com um expressivo aumento no ano de 1989. Porém, em termos absolutos, o total transportado nesta bacia foi inferior ao de 1987, enquanto na bacia Nordeste, a navegação já havia se extinguido em 1986. Segundo os dados disponíveis, sua paralisação se deu em um momento de elevação do volume de carga transportada. Em 1980 foram transportadas 2391 ton, elevando-se para 17195 ton no ano de 1985. Entretanto, devido à carência de informações, certamente estes dados necessitam de análise mais consistente, pois estão incompletos.

\section{Contradições do desenvolvimento do Vale do São Fran- cisco}

O Vale do São Francisco, considerado a partir do desenvolvimento econômico brasileiro, não deixa dúvidas quanto ao seu atraso crônico, destacando-se que toda a bacia banhada por esse grande rio recebia pomposas propostas de investimentos por parte do Estado, que nunca se concretizaram, exceto em alguns momentos pontuais e, às vezes, indiretamente, como é o caso da chegada das pontas dos trilhos de ferro ao Vale, respectivamente, em 1896 e 1910. Com relação a sua posição estratégica, ele serviu de canal de embrenhamento e controle em todo o processo histórico brasileiro. Durante o período colonial a presença do Estado foi marcante, particularmente no decorrer do ciclo do ouro, não só pelas cartas régias e decretos, mas também por seus agentes de controle, como fiscais, militares e aliados (a serviço da Coroa). Tendo como eixo básico o rio, questões geopolíticas, de Segurança Nacional e controle do território foram pilares estratégicos do Estado após a Independência do Brasil com vista à unidade e ocupação do território brasileiro. A preocupação com 0 povoamento do interior perdurou até o século $X X$, resultando na construção de Brasília.

Todos os estudos feitos ao longo da história mostram que as questões de integração, unidade e controle sempre estiveram presentes no Vale do São Francisco. Entretanto, nunca foram destinados investimentos suficientes, pois não há registro de construções de quartéis, postos fiscais e delegacias de vigilância federal. Embora, para esse caso, não fosse necessariamente pre- 
ciso contar com corpo de segurança atuando na região, trata-se de uma questão de "panactismo", ou seja, não é preciso ver os guardas, basta saber que eles estão vigiando, mesmo de longe. Historicamente o Vale do São Francisco foi palco de inúmeros conflitos políticos e sociais. Inicialmente, as batalhas ocorreram entre índios e colonizadores e, posteriormente, foram travadas entre grandes proprietários de terra da região, com a participação dos seus vaqueiros e agregados. Esses fundiaristas deram origem aos "coronéis". Apesar da rivalidade entre os "coronéis" do Vale, assim como em outras partes do interior em busca do poder econômico e do controle político local, eles foram guardiões da ordem estabelecida nos sertões.

Figura 1 Evolução do transporte hidroviário brasileiro gerado em cinco bacias hidrográficas do Brasil (ton).

\begin{tabular}{|c|c|c|c|c|c|c|}
\hline Ano & São Francisco & Amazônica & Prata & Nordeste & Sudeste & Total $(\%)$ \\
\hline 1964 & 25.466 & & & & & \\
\hline 1965 & 50.490 & & & & & \\
\hline 1966 & 54.639 & 205.228 & 231.103 & 34.209 & 1.047 .648 & $1.572 .593 \quad(3.4)$ \\
\hline 1967 & 42.302 & 177.363 & 330.285 & 27.122 & 1.072 .648 & $1.649 .720 \quad(2.6)$ \\
\hline 1968 & 53.142 & 233.768 & 177.705 & 16.873 & 889.781 & $1.381 .269 \quad(3,8)$ \\
\hline 1969 & 48.669 & 324.350 & 203.966 & 20.272 & 600.891 & $1.198 .148 \quad(4.1)$ \\
\hline 1970 & 57.948 & 316.557 & 201.464 & 20.246 & 646.142 & $1.242 .357 \quad(4,1)$ \\
\hline 1971 & 29.759 & 356.515 & 262.943 & 9.458 & 841.229 & $1.449 .904 \quad(4,7)$ \\
\hline 1972 & 35.541 & 536.982 & 275.277 & 8.785 & 807.682 & $1.662 .207(2.0)$ \\
\hline 1973 & 30.862 & 565.366 & 342.347 & 9.728 & 849.780 & $1.798 .083 \quad(1.7)$ \\
\hline 1974 & 31.664 & 540.570 & 422.122 & 14.346 & 1.550 .194 & $2.558 .896 \quad(1,2)$ \\
\hline 1975 & 32.832 & 586.907 & 272.389 & 9.690 & 1.786 .367 & $2.688 .185 \quad(1.2)$ \\
\hline 1976 & 32.050 & 676.707 & 119.863 & 7.523 & 2.104 .213 & $2.940 .356 \quad(1,1)$ \\
\hline 1977 & 18.638 & 769.441 & 475.651 & 7.389 & 2.158 .910 & $3.430 .029 \quad(0.6)$ \\
\hline 1978 & 20.221 & 844.280 & 264.690 & 4.634 & 2.654 .690 & $3.787 .917 \quad(0.5)$ \\
\hline 1979 & 22.756 & 1.149 .411 & 507.524 & 4.751 & 2.679 .916 & $4.364 .358 \quad(0.5)$ \\
\hline 1980 & 33.267 & 1.466 .830 & 361.476 & 2.391 & 2.823 .324 & $\begin{array}{ll}4.687 .288 & (0.7)\end{array}$ \\
\hline 1981 & 39.969 & 1.513 .088 & 289.405 & 3.154 & 3.222 .498 & $5.068 .144 \quad(0.8)$ \\
\hline 1982 & 56.158 & 1.513 .117 & 289.890 & 2.298 & 3.720 .067 & $5.898 .392 \quad(1,0)$ \\
\hline 1983 & 62.206 & 1.515 .140 & 208.271 & 3.705 & 3.990 .598 & $5.779 .920 \quad(1,1)$ \\
\hline 1984 & 40.248 & 1.599 .980 & 145.247 & 13.344 & 4.020 .980 & 5.819 .582 \\
\hline 1985 & 56.738 & 2.217 .270 & 463.433 & 17.195 & 4.151 .518 & 7.012 .518 \\
\hline 1986 & 84.812 & 2.286 .834 & 625.197 & & 4.070 .043 & 7.264 .702 \\
\hline 1987 & 113.754 & 2.4052442 & 763.443 & & 4.469.674 & 7.864 .803 \\
\hline 1988 & 115.901 & 2.621 .181 & 889.646 & & 3.925 .417 & 7.712 .286 \\
\hline 1989 & 94.063 & 2.373 .665 & $825.437^{*}$ & & 4.111 .914 & 7.550 .148 \\
\hline
\end{tabular}

FONTES: Relatórios do Ministério dos Transportes, GEIPOT, 1964 a 1990. Anuário Estatístico dos Transportes, GEIPOT, 1965 a 1989.

Os coronéis travaram muitas batalhas no interior do pais, dividiam o poder com a força das armas e tinham como soldados, os jagunços, vaqueiros e moradores. Mesmo assim a "ordem era mantida" nessas localidades, exceto em algumas ocasiões especiais em que a situação escapava ao controle. Nesse contexto, os coronéis sempre foram importantes vigias e mantenedores da ordem, da lei e do controle das regiões onde viviam. Tanto que nos anos de 1925-1926, participaram ao lado das forças legais no combate à Coluna Prestes, inclusive no Vale do São Francisco. Portanto, nesta situação não era necessária a construção de quartéis, delegacias federais ou outros mecanismos de controle. Em caso de necessidade de deslocamento de tropas, isso se daria por meio do transporte ferroviário e hidroviário no rio São Francisco. Com isso, assegurava-se o controle físico e político de extensas áreas do interior brasileiro.

A partir da década de 1940, particularmente após o fim da Segunda Guerra Mundial, ocorreram novas propostas de desenvolvimento com outros parâmetros. A primeira medida com- creta se deu quando a Assembléia Constituinte de 1946 destinou $1 \%$ das receitas tributárias federais para a elaboração de um Plano de Valorização do Vale do São Francisco. Essa distribuição de recursos foi estabelecida para um período de 20 anos. Sua medida mais importante, com vista ao desenvolvimento regional, foi a criação da Comissão do Vale do São Francisco (CVFS), em 1948. Destacamos que, paralelamente às medidas previstas acima, o rio São Francisco era contemplado em mais um Plano Nacional de Viação para o país, elaborado em 1947, com o objetivo de realizar a integração do transporte terrestre com o fluvial, mas essa medida não se concretizou.

Com esse Plano, o "Velho Chico" mais do que nunca continuou reforçando sua importância estratégica de sempre, naquele momento marcado pelos efeitos da Segunda Guerra, que ainda estavam bem presentes. Tomar medidas preventivas contra uma possivel interrupção da navegação de cabotagem era fundamental, como ocorreu durante a guerra, em que 0 rio foi escolhido para estabelecer a ligação entre as regiões Nordeste e 
Sudeste. Com isso, a inclusão do São Francisco como via de interesse imprescindível da nação era uma decisão coerente e sintonizada com os acontecimentos daquele momento histórico. Portanto, uma via de comunicação com a importância estratégica do rio São Francisco não poderia continuar operando com um nível de transporte tão precário. Esta conjuntura contribuiu inclusive para decisão do Governo Central de implementar novos projetos de desenvolvimento no Vale do São Francisco e contou com a indiscutível participação do Parlamento Brasileiro.

O fim da Segunda Guerra Mundial e do Estado Novo possibilitou o surgimento de novos horizontes políticos, econômicos e culturais para o país, em que o debate em torno do desenvolvimento das forças produtivas era parte significativa do processo; o Vale do São Francisco também foi incluído na nova etapa vislumbrada pelos ventos do pós-guerra e pós-ditadura. Nesse contexto, o rio São Francisco representa dramaticamente o retrato da situação brasileira, transportando consigo a pujança e a esperança em um cenário de extrema carência, ou seja, a água é indiscutivelmente uma riqueza de primeira grandeza para a região atravessada pelo rio. Ao mesmo tempo, era a base do desenvolvimento da imensa região banhada pelo grande "Rio da Unidade Nacional", mas, por outro lado, poderia em breve ser um eixo de fortes conflitos que provocariam efeitos políticos e sociais incalculáveis. Por isso, a elaboração da Lei oo 541, de 15 de dezembro de 1948, que criou a CVSF, foi um passo importante.

Nesse contexto, o Vale passou a receber as devidas atenções a que tinha direito, o reconhecimento da sua importância e, ter um novo tratamento, sempre tendo o rio como referência de todas as ações previstas para a região, pois sua água era a principal riqueza. $O$ Velho Chico foi e continua sendo 0 eixo norteador das propostas de um amanhã diferente para toda a gente do grande Vale e do Brasil em geral. A materialização de tais projetos se deu inicialmente com a Constituição de 1946, que destinava $1 \%$ do orçamento da União para investir no Vale e proporcionar o seu desenvolvimento. Um primeiro passo já havia sido dado com a criação da Companhia Hidrelétrica do São Francisco-CHESF, no ano anterior, que nas décadas seguintes implantou várias usinas hidrelétricas.

\section{0 acesso à terra e o desenvolvimento do Vale: um dile- ma a ser resolvido}

A posse da terra é uma questão que sempre esperou a sua vez. A SUVALE, substituta da CVSF, também focou esse problema elaborando medidas para as sua mudança, embora as propostas da CVSF continuassem atuais e pudessem ser execu- tadas. A SUVALE teve pouca duração e suas realizações em posse da terra ficaram aquém dos seus propósitos.

Em seguida, veio a Companhia de Desenvolvimento do Vale São Francisco (CODEVASF), empresa pública criada pela Lei no 6088 , de 16 de julho de 1974. a CODEVASAF deparou-se com antigos problemas que não foram resolvidos até o presente, embora tenha sido indiscutível o seu sucesso na condução dos grandes projetos agrícolas, principalmente aqueles ligados ao desenvolvimento da fruticultura irrigada no Submédio São Francisco, região que compreende Petrolina (PE), Juazeiro (BA) e 0 entorno destes municípios. Esta atividade, segundo SILVA (2001), inseriu de vez a região no mercado nacional e internacional de frutas tropicais e adaptadas, como a uva.

A inclusão da maioria dos trabalhadores do Vale pelo acesso à posse da terra não foi possível em nenhuma das etapas de desenvolvimento do Vale do São Francisco, nem quando a maioria da população vivia no campo, nem após as décadas de 1980 e 1990, período em que o meio rural já estava bastante esvaziado. Ainda não se encontrou uma solução adequada para aqueles trabalhadores que permaneceram no Vale. Estes necessitam do acesso a terra para a produção de riqueza e geração de renda, um instrumento de inclusão. A pequena propriedade continua numericamente predominando no Vale em busca de novas orientações políticas, econômicas e técnicas que assegurem a melhoria de vida dos seus donos e das suas famílias. Segundo BELIK (2000), nem a criação do Programa de Valorização da pequena Produção Rural (PRONAF) conseguiu alterar tal situação da agricultura familiar.

Embora o êxito dos grandes projetos de desenvolvimento implantados na região seja uma realidade, caracterizam-se por serem excludentes, ou seja, deixam de fora a maioria dos trabaIhadores do grande Vale, onde a pobreza continua inabalável sem alterar sua marca histórica, apesar da modernização de alguns setores econômicos existentes das nascentes do rio São Francisco e seus afluentes até a foz. FRANÇA (2001) mostra que a agricultura irrigada com tecnologia que avança em região semiárida poderá se transformar no indutor do processo de desenvolvimento regional. $\mathrm{O}$ grande desafio é implementar uma política econômica em que a maioria dos trabalhadores rurais e urbanos seja incorporada, isso ainda não ocorreu, apesar dos Perímetros de Irrigação continuarem gerando emprego na região do Vale, sobretudo, no pólo de Petrolina e Juazeiro.

A cultura de uva no Vale transformou-se em estrela de primeira grandeza entre as frutas do Perímetro de Irrigação, rivalizando apenas com a manga, também detentora de grande 
brilho, tanto no mercado nacional quanto no externo. SILVA (2001) destaca que a área ocupada com o plantio de uva passou de 893 ha em 1987, para 3767 ha no ano de 1999, ou seja, um aumento de $321,83 \%$ no período de 12 anos, um crescimento médio anual de $26,82 \%$. SILVA, também chama atenção para a oscilação das exportações que em 1991, foi de 10500 ton e nos anos de 1993 e 1994, de 10000 ton em cada ano e, em 1997, apenas 3700 ton, voltando a crescer em 1998, com 4550 ton. Apesar das quedas cíclicas, perdurou a tendência de um elevado crescimento das exportações neste período de 7 anos, sendo que estimativa para o ano de 1999 era de 6000 ton. Os dados da Valexport mostram que neste ano foram exportados 10250 ton. As exportações de uva produzida no Vale continuaram a crescer. Em 2000, atingiram 15300 ton, em 2001, passaram para 19627 ton e no ano de 2002, alcançaram 25087 ton.

Com isso, conclui-se que o dinamismo da cultura vinícola e de outras frutas em terras sertanejas do Submédio São Francisco nos primeiros 15 anos de sua atividade é algo espetacular, além da produção realizada em Pirapora, no Alto Vale. Entretanto, os benefícios proporcionados continuam limitados a um reduzido grupo social local e o espetáculo do "crescimento" só tem lugar para uns poucos. Com isso, os críticos deste processo lembram que essa estrutura pode até gerar riquezas, mas distribuir renda jamais, mesmo empregando um considerável número de pessoas no conjunto das atividades diretas e indiretamente ligadas aos projetos de irrigação, principalmente aqueles situados no Submédio São Francisco.

A área ocupada com o plantio de uva no Submédio São Francisco era de 3767 ha em 1999. Os dados apresentados por SILVA (2001) mostram que Pernambuco contava com 2503 ha distribuídos em 6 municípios, sendo que Petrolina tem a maior parcela do cultivo de uva com 1602 ha e Orocó, a menor área com apenas oito hectares cultivados. A Bahia vem logo em seguida com uma área bem menor, entorno de 1263 ha, sendo que a maior parcela 756,2 ha está situada em Juazeiro, Curuçá com 110,3 ha, Casa Nova 219,1 ha e de Sobradinho não há dados disponíveis. Outras localidades do Vale do São Francisco, também produzem uva (em menor escala). Bom Jesus da Lapa nos projetos Formoso $\mathrm{A} \mathrm{e} \mathrm{H}$, no Distrito de Irrigação de Formoso e usam a água do rio Corrente. No Médio Vale, a uva é produzida na região de Barreiras (BA), Jaíba e no Projeto Jaíba em Matias Cardoso (MG). No Alto São Francisco ocorre em Pirapora e Várzea da Palma (MG). A produção de uva em Pirapora é a mais expressiva fora do Perímetro de Irrigação do Submédio Vale. Sua safra em 1998, foi de 2512 ton.
A cultura de videira continua se expandindo, segundo a CODEVASF, embora não disponha de números que expressem este crescimento. LEÃO e POSSÍDIO (2000), lembram que a uva em termos culturais é uma planta italiana e francesa que foi introduzida na Bahia e em Pernambuco desde o século XVIII, e avançou para 0 interior até 0 limite do Agreste com 0 Sertão. Cabe reafirmar o sucesso da presença desta planta oriunda de região temperada no trópico e semi-árido.

A produção de manga no Perímetro de Irrigação do Submédio São Francisco, se dá paralelamente à vinicultura. $\mathrm{A}$ maior parte da produção de manga do Brasil destina-se ao consumo interno, inclusive a produzida no Vale, isto porque as variedades tradicionais são bastante fibrosas e têm pouca aceitação no mercado externo. A expansão do cultivo da mangueira irrigada no Submédio Vale foi extraordinário. SILVA (2001) destaca que em 1987 havia no pólo 921 ha ocupados com manga, que, em 1996, já eram 3200 ha e, em 1999, alcançavam 12456 ha, distribuídos por seis municípios pernambucanos e quatro baianos. Em apenas três anos o seu aumento foi de $389,2 \%$, ou seja, um crescimento anual de $129,7 \%$, o que representa 3,31 vezes a área ocupada pela vinicultura na região.

Os dados apresentados por SILVA mostram que, em 1996, a região do pólo de irrigação do Submédio Vale foi responsável por 70\% das exportações brasileiras de manga. Em 1991, a região exportou 3300 ton para o mercado externo e 15000 ton em 1994. No ano seguinte ocorreu uma expressiva queda de $25 \%$, baixando para 12000 ton, segundo a Valexport (2003). Em 1998, a sua exportação elevou-se para 34000 ton, no ano de 2000, atingiu 57200 ton e, em 2001, elevou-se para 81115 ton. Este volume representou em média, $90 \%$ das 193559 ton de manga destinada à exportação entre 1997 e 2002.

0 processo de irrigação desenvolvido em todo 0 Vale do Velho Chico produz as mais variadas culturas, incluindo as frutas voltadas para o mercado externo e as culturas características da época das vazantes: milho, feijão, arroz, mandioca, batata doce e cebola, que compõem a alimentação básica da população regional e do país como um todo. Estas culturas não receberam atenção especial das políticas públicas para a agricultura no Vale, pois elas não interessavam as empresas do setor. No entanto, 0 Estado assegurou todo apoio necessário às grandes empresas, ao mesmo tempo elas atenderam de pronto o chamado. Elas partiram para o "sacrificio" sem o risco de seus investimentos naufragarem em aventuras sertanejas. Nada de risco capitalista e tampouco cultivar culturas tradicionais e frutas com mercado limitado, seja interno ou externo. Apesar destes reparos, em 
particular, a produção de bananas em larga escala vem sendo realizada por grandes empresas, pois esta fruta tem um enorme mercado à sua disposição, sobretudo nas grandes cidades das regiões Sudeste e Nordeste, além de contar com a participação dos pequenos produtores.

Em termos estratégicos e econômicos, para as grandes empresas (sobretudo as internacionais) é melhor deixar a maior parte da produção de mamão, melancia, banana, goiaba, acerola, maracujá, além de outras, para os "terráqueos" locais (pequenos e médios produtores), porque estas empresas preferem participar na comercialização e, o mínimo possível, na produção destas frutas. No entanto, dominam a produção e comercialização de frutas como manga e uva, denominadas de pérolas do complexo frutífero do Submédio São Francisco. Antes mesmo desta grande expansão observada acima, SORJ (1980) lembra que os projetos de irrigação permitem a instalação de empresas agroindustriais que passam a controlar grandes parcelas de terras irrigadas. Escolhem o que vão produzir, e para os pequenos produtores restam os pequenos lotes que serão subordinados à agroindústria porque estes não dispõem de meios para produzir as culturas de seu interesse. Além do mais, sem investimentos e possuindo propriedades com áreas limitadas, não Ihes restam outro papel senão o de apêndice do sistema.

Para os críticos deste modelo, o amplo processo de desenvolvimento designado para o Vale resultou em reduzido número de atividades agrícolas ancoradas na fruticultura irrigada que, segundo UNGER (2001), consome vultosos investimentos e atende aos interesses, principalmente, das empresas multinacionais. A autora lembra que a transformação do Sertão do Submédio São Francisco em uma Nova Califórnia não melhorou em nada a vida dos ribeirinhos da região, os rumos desta política de exclusão no desenvolvimento do Vale têm que ser alterados. Os dados apresentados por GOMES (2001) reforçam os questionamentos feitos por Nancy UNGER, visto que nos seis projetos de Petrolina e Juazeiro, os investimentos públicos foram da ordem de 674 milhões de Reais, enquanto os investimentos privados aplicados em seus próprios projetos foram em torno de 604 milhões de Reais, ou seja, representam $47,26 \%$ dos investimentos globais (públicos e privados) investidos na região (dados de 1999). Os sindicatos dos trabalhadores rurais da região, juntamente com as dioceses de Juazeiro e Barra (BA), também engrossam as fileiras dos críticos ao modelo de desenvolvimento implantado no Vale, principalmente no Submédio São Francisco.

GOMES (2001) destaca que entre 1960 e 1996 ocorreu um espetacular crescimento da População Economicamente Ativa no pólo de irrigação de Petrolina. Trata-se de uma elevação em torno de 543\%. Em 1960, Petrolina contava com 10478 habitantes e passou para 67388 em 1996, enquanto Juazeiro passou de 19248 para 57519 no mesmo período. Nestes 36 anos foram criados 102.181 novos empregos no pólo de irrigação. Contudo, GOMES mostra que, em 1998, as pessoas diretamente empregadas no perímetro de irrigação tinham um salário médio de $R \$ 254,00$, equivalente a dois salários mínimos da época ou a US\$ 86,69, em 2004. Trata-se de uma remuneração baixa, mesmo porque uma parte da renda gerada com a irrigação é a apropriada como renda do capital e não do trabalhador. Ou seja, não se pode interpretar 0 valor acima como renda, conclui o autor. Estes dados contribuem bastante com o combustível dos críticos deste modelo, porque estas médias não levam em conta os agricultores com diferentes níveis de produtividade.

Finalmente temos a proposta de transposição de parte da água do rio São Francisco para outras bacias do semi-árido nordestino que se materializou pela primeira vez em 1847, com 0 Imperador Dom Pedro II. A construção dos canais deveria ser executada num período de 10 anos. Contudo, esta questão já havia sido cogitada antes. Segundo PESSOA (1989), a idéia da transposição se reporta ao governo de Dom João VI, no período colonial, quando foram autorizados estudos de viabilidade desta medida. A construção de canais para a transferência de água já era difundida em várias partes do mundo. Neste sentido, a idéia de transposição formulada por Dom João não chegou a ser uma novidade. No entanto, na porção oriental da América do Sul, a sua concepção e possível execução realmente seria algo espantoso em termos técnicos e operacionais. Esta obra seria inviável por conta do relevo que exigiria a elevação da água a uma altura de $160 \mathrm{~m}$. Não havia energia para assegurar o funcionamento deste sistema. Porém, foi a partir do governo de Dom Pedro II que a transposição do São Francisco entrou na agenda governamental e nunca mais saiu. CARVALHO (1988) aponta que os primeiros estudos a respeito da transferência de água do Velho Chico para outras bacias do semi-árido (Jaguaribe) foram realizados por Antônio M. de MACEDO e sua divulgação ocorreu pela primeira vez em 1847, quando suplente de deputado no Ceará.

Apesar de ser um Projeto bastante antigo, é muito polêmico. A sua implantação vem recebendo fortes críticas inclusive na própria região que será beneficiada por ele. 0 documento elaborado pela Universidade Federal do Rio Grande do Norte, denominado A Transposição do Rio São Francisco e o Rio Grande do Norte (2000), além de fazer uma consistente crítica ao Projeto, é de parecer contrário. 
Tabela 2 Localização e extensão das áreas ocupadas pelos projetos da CODEVASF.

\begin{tabular}{|c|c|c|c|c|}
\hline Projetos e Perímetros & Municípios & $\begin{array}{l}\text { Área Total } \\
\text { em ha }\end{array}$ & $\begin{array}{l}\text { Área ocupada } \\
\text { em ha }\end{array}$ & $\begin{array}{l}\text { Baixo, Médio e Alto } \\
\text { São Francisco }\end{array}$ \\
\hline MARITUBA & Penedo-AL & 3.136 & 894 & Baixo \\
\hline BOACICA & Igreja Nova-AL & 3.334 & 3.334 & Baixo \\
\hline ITIUBA & Porto Real do Colégio-AL & 894 & 894 & Baixo \\
\hline BETUME & I. Flores, Neópolis e Pocatuba-SE & 2.865 & 2.865 & Baixo \\
\hline COTINGUIBA/PINDORA & Japoatã, Neópolis e Propriá-SE & 2.237 & 2.832 & Baixo \\
\hline \begin{tabular}{|l} 
PROPRIÁ \\
\end{tabular} & C.São João, Propriá, e Telha-SE & 1.777 & 1.777 & Baixo \\
\hline QUIXABEIRA & Canindé do São Francisco-SE & 3.668 & & Baixo \\
\hline BREJO DE SANTA MARIA & Santa Maria da Boa vista-PE & 3.800 & & Sumédio \\
\hline PONTAL/SOBRADINHO & Dormentes e Petrolina-PE & 27.930 & & Submédio \\
\hline PONTAL & Petrolina-PE & 7.862 & & Submédio \\
\hline BEBEDOURO & Petrolina-PE & 2.418 & 2.412 & Submédio \\
\hline NILO COELHO & Casa Nova-BA e Petrolina-PE & 22.061 & 20.877 & Submédio \\
\hline PAULO AFONSO & Paulo Afonso-BA & 7.000 & & Submédio \\
\hline CURUÇÁ & Juazeiro-BA & 4.350 & 4.350 & Submédio \\
\hline MANIÇOBA & Juazeiro-BA & 4.293 & 4.293 & Submédio \\
\hline TOURÃO & Juazeiro-BA & 13.188 & 10.710 & Submédio \\
\hline MANDACARU & Juazeiro-BA & 419 & 419 & Submédio \\
\hline SALITRE & Juazeiro-BA & 31.305 & & Submédio \\
\hline CRUZ DAS ALMAS & Casa Nova-BA & 38.400 & & Submédio \\
\hline FORMOSO-A e H & Bom Jesus da Lapa-BA & 12.716 & 10.656 & Médio \\
\hline CORRENTINA & Corret.,S M.Vitória, Santana-BA & 141.000 & & Médio \\
\hline FORMOSINHO & Coribe-BA & 448 & 448 & Médio \\
\hline JABORANDI & Coribe e Jaborandi-BA & 23.000 & & Médio \\
\hline NUPEBA & Riachão das Neves-BA & 3.318 & 3.318 & Médio \\
\hline RIACHO GRANDE & Riachão das Neves-BA & 1.985 & 1.985 & Médio \\
\hline BARREIRAS NORTE & Barreiras-BA & 2.895 & 2.520 & Médio \\
\hline SÃO DESIDÉRIO, BAR. SUL & São Desidério e Barreiras-BA & 2.238 & 2.238 & Médio \\
\hline BAIXIO IRECÊ & Itag. Da Bahia e Xique-Xique-BA & 59.630 & & Médio \\
\hline MIRORÓS & Gentio de Ouro e Ibipeba-BA & 2.1666 & 2.097 & Médio \\
\hline VALE DO IUIÚ & lutú, Malhado e P.M. Alto & 88.306 & & Médio \\
\hline CERAÍMA & Guanambí-BA & 430 & 408 & Médio \\
\hline ESTREITO I, III e IV & Sebastião Laranjeira e Urandi-BA & 7.943 & 2.099 & Médio \\
\hline JAÍBA & Jaíba e Matias Cardoso-MG & 100.000 & 156.770 & Médio \\
\hline LAGOA GRANDE & Januaúba-MG & 1.660 & 1.538 & Médio \\
\hline GORUTUBA & Nova Porterinha-MG & 5.286 & 5.286 & Médio \\
\hline JEQUITAÍ & C. Poções, Navarro, Jequitai-MG & 34.605 & & Médio \\
\hline PIRAPORA & Pirapora-MG & 1.261 & 1.261 & Alto \\
\hline RIO DAS VELHAS & Várzea da Palma-MG & 25.000 & & Alto \\
\hline Totais & & 698.524 & 103.173 & \\
\hline
\end{tabular}

Fonte: CODEVASF, 2002.

De acordo com o Projeto de Integração do Rio São Francisco com Bacias Hidrográficas do Nordeste Setentrional (2004), serão construídos dois grandes canais (eixos) para levar a água do "Rio da Unidade Nacional" para outras bacias. O Ponto inicial deste EIXO NORTE, com 402 km, situa-se em Cabrobó e conduzirá, em média, $45,2 \mathrm{~m}^{3} / \mathrm{s}$ de água captada no rio São Francisco. Uma vez elevada a $165 \mathrm{~m}$, seguirá por gravidade para as bacias dos rios Brígida, Terra Nova, Jaguaribe, Apodi e Piranhas-Açu. A extensão do EIXO LESTE é estimada em 220 $\mathrm{km}$. Será tirada água de Itaparica e feito o bombeamento a uma altura de 402 m para os rios Paraíba e Moxotó que deságuam respectivamente, no oceano Atlântico e no rio São Francisco. As obras do EIXO NORTE foram estimadas em 1 bilhão e 30 milhões de dólares e as do EIXO LESTE em 472 milhões de dólares. 
A construção desses canais dotará de infra-estrutura permanente uma região bastante populosa do sertão e do agreste nordestino. O Ministério da Integração Nacional, responsável pelo projeto, garante que os benefícios desse empreendimento devem abranger a maioria da população, caso contrário não se justificaria sua realização. A água transportada por estes canais vai atender a: (1) 4,4 milhões de habitantes na Região Metropolitana de Fortaleza através do rio Jaguaribe e do Canal do Trabalhador, construído no início da década de 1990; (2) 1,5 milhões de habitantes na bacia do rio Paraíba; (3) 1,1 milhões de habitantes no agreste de Pernambuco; e (4) 1,3 milhões habitantes nas bacias do Apodi e Piranhas-Açu.

O Ministério estima a criação de 180 mil empregos no decorrer da implantação e consolidação do Projeto de Integração pela da posse da terra ou do trabalho assalariado nas atividades econômicas a serem criadas. O Governo espera que até 2025, aproximadamente 400 mil pessoas do meio rural e 600 mil dos centros urbanos, totalizando um milhão de pessoas, permanecerão na região de abrangência. A bacia do rio São Francisco tem $640 \mathrm{mil} \mathrm{km}^{2}$, mas, com a inclusão da área atendida pelo Projeto, passa para $787 \mathrm{mil} \mathrm{km}^{2}$, chamada Área de Influência Indireta. As bacias receptoras têm 212 mil km² $^{2}$ e, em 2025, receberão 42,4 $\mathrm{m}^{3} / \mathrm{s}$.

\section{Consideração final}

O planejamento federal foi retomado de forma intensificada a partir da década de 1990 no Brasil, privilegiando a escala municipal, lócus privilegiado das políticas públicas, dos conflitos e disputas pelo poder. As novas institucionalidades que possibilitam formas de ampla participação de diversos setores em discussões, como a das águas, se assentam sobre perversas tradições hierárquicas e têm sido apropriadas por antigos e "novos" agentes hegemônicos. Aos Geógrafos cabe maior consciência de sua importância técnica, teórica e política. 
CAMELO FILHO, J. V. (2005) Political, economical and social dynamics of São Francisco River and its valley. Revista do Departamento de Geografia, n. 17, p. 83-93.

Abstract: The São Francisco River was always an important linking channel among Brazil Northeast, Southeast and Centro-Oeste regions, through fluvial navigation. Strategically, this river and its branches have contributed to the control and settlement in the interior of Brazil, where, along history, the large and the small properties were constituted. Both are responsible for the economic and social underdevelopment of the São Francisco Valley. Its economy, till the first half of the twentieth century, was supported by the extensive cattle growing and by the subsistence agriculture. The possession or the access to the land, for most part of the population, has been a big challenge to the Government. Along the last 50 years, the water of the Old Chico has become one of the biggest richness of the São Francisco Valley and the main raw material to its development that has effectively begun with the generation of electric energy in Paulo Afonso. From the beginning of the eighty and ninety decades, the irrigation process has been intensified, aiming, in especial, the production of fruits in the irrigation perimeter of Petrolina and Juazeiro, west of Bahia State, in the Jaiba Project and Pirapora, in Minas Gerais State. However, during the last years, the Project of Transposition of Water from the São Francisco River to other hydrographic basins of the semi arid region has got prominence.

Key words: São Francisco River; Navigation; Water; Development; Irrigation; Property.

Recebido em 7 de setembro de 2005, aceito em 2 de outubro de 2005.

\section{Referências}

UFRN (2000) A Transposição do Rio São Francisco e o Rio Grande do Norte. Natal: UFRN.

ABREU, J.C. (1975) Caminhos antigos e povoamento do Brasil. 4 ed. Brasília: Civ. Brasileira. INL-MEC.

BELIK, W. (2000) PRONAF: Avaliação da Operacionalização do Programa. In: O Novo Rural Brasileiro - Políticas Públicas. Campinas: UNICAMP.

BLOCH, D. (1996) As Frutas Amargas do Velho Chico. Irrigação e Desenvolvimento no Vale do São Francisco. São Paulo: Livro da Terra.

BURTON, R. (1977) Viagem de Canoa de Sabará ao Oceano Atlântico. São Paulo: Ed. USP.

CARVALHO, O.A.E. (1988) Política do Nordeste. Rio de Janeiro: Ed. Campus.

FIGUEIREDO, L. (1941) Cidades e Sertões. Rio de Janeiro: Min. da Guerra.

FRANÇA, F.M.C. (Org.) (2001) A Importância do Agronegócio da Irrigação para o Desenvolvimento do Nordeste. Fortaleza: Banco do Nordeste.

FURTADO, C. (1972) Análise do Modelo Brasileiro. Rio de Janeiro: Civ. Brasileira.

GOMES, G.M. (2001) Velhas Secas em Novos Sertões. Continuidade e Mudanças na Economia do Semi-árido e dos Cerrados Nordestinos. Brasília: IPEA.

IBGE (1940) Anuário Estatístico do Brasil. Rio de Janeiro: IBGE, 1939/1940.
IBGE (1977) Geografia do Brasil, Grande Reg Sudeste. Rio de Janeiro.

LEÃO, P.C.S.; PASSIDIO, E.L. (2000) História da Videira. In: A Vinicultura no Semi-Árido Brasileiro. Petrolina: EMBRAPA.

MACHADO, F.M. (2002) Navegação do Rio São Francisco. Rio de Janeiro: Topboaks.

PESSOA, D. (Org.) (1989) Transposição do Rio São Francisco: A Dimensão Socioeconômica. Recife: Ed. Massagana/FJN.

IBGE (1963) Plano de Valorização Econômica do Vale do São Francisco: Documentos Parlamentares (CXIII), Câmara dos Deputados. v. I e II. Brasília: DDP.

BRASIL (2004) Projeto de Integração do Rio São Francisco com Bacias Hidrográficas do Nordeste Setentrional. Brasília: MI.

SANTOS, R.M. (1985) O Rascunho da Nação: formação, auge e ruptura da economia colonial. Tese de Doutorado. Campinas: UNICAMP.

SILVA, P.C.G. (2001) Articulação do interesse público e privado no Pólo Petrolina-PE / Juazeiro-BA. Em busca de espaço no mercado globalizado de frutas frescas. Tese de Doutorado. Campinas: UNICAMP.

EMBRAPA (2000) Semi-Árido Brasileiro. Petrolina: EMBRAPA.

SORJ, B. (1980) Estado e Classe sociais na Agricultura Brasileira. Rio de Janeiro: Ed. Guanabara.

THERY, H. (1980) O Vale do São Francisco, uma Região Subdesenvolvida e sua Valorização. Ciência e Cultura, São Paulo, agosto.

UNGER, N.M. (2001) Da Foz à Nascente. O Recado do Rio. São Paulo: Cortez/UNICAMP. 